\title{
A Cost-Effectiveness Analysis Comparing the VivaSight Double-Lumen Tube and a Conventional Double-Lumen Tube in Adult Patients Undergoing Thoracic Surgery Involving One-Lung Ventilation
}

\author{
Sara Larsen ${ }^{1}\left[\right.$ • Jimmy Højberg Holm² $\cdot$ Tove Nørgaard Sauer $^{2} \cdot$ Claus Andersen $^{2}$
}

Published online: 11 July 2019

(c) The Author(s) 2019

\begin{abstract}
Background One-lung ventilation (OLV) procedures are essential for most thoracic surgeries, and the most common method is intubation with a conventional double-lumen tube (cDLT) and bronchoscopy to verify correct tube placement.

Objective The objective of this study was to conduct a cost-effectiveness analysis comparing the VivaSight double-lumen tube (DL) and a cDLT for OLV procedures.

Methods A cost-effectiveness analysis was conducted from a healthcare sector perspective in Denmark using a decision analytic model to assess the potential effects and costs of using VivaSight-DL as an alternative to a cDLT with a reusable bronchoscope. Costs were determined using a micro-costing approach. The effectiveness measure was the number of times that fiberoptic confirmation of the tube placement during intubation or surgery was unnecessary and thus avoided. The effectiveness input was from a randomized controlled trial $(n=52)$. Both deterministic and probabilistic sensitivity analyses were conducted to assess the robustness of the results.

Results Fiberoptic confirmation of tube placement was only necessary in two (6.66\%) procedures using VivaSight-DL. The cost of using VivaSight-DL was \$US299.96 per procedure versus \$US347.61 for a cDLT with a reusable bronchoscope. The incremental cost-effectiveness ratio was $-\$$ US51.06 per bronchoscopy avoided. The base-case analysis indicated that the use of VivaSight-DL was cost effective compared with the use of a cDLT with reusable bronchoscope. Sensitivity analyses showed that the results were robust and that VivaSight-DL was more effective and less costly.

Conclusion This study suggests that VivaSight-DL is associated with cost savings and reductions in bronchoscope use to verify correct tube placement. The conclusion is based on the results from a single institution. To clarify whether VivaSightDL is cost effective in larger or global clinical settings, further economic evaluations should be performed.
\end{abstract}

\section{Introduction}

One-lung ventilation (OLV) is an essential technique for most classic thoracic surgeries and refers to the mechanical separation of the lungs, whereby one lung is ventilated and the other is deflated [1-4]. The most common OLV method is intubation with a double-lumen tube (DLT) $[1-3,5]$. Indications for OLV procedures are often lobectomies, biopsies for suspicion of cancer, and lung

Sara Larsen

larsenbk@hotmail.com

1 Aalborg University, Niels Jernes Vej 10, 9220 Aalborg, Denmark

2 Odense University Hospital, J.B. Winsløws Vej 4, 5000 Odense, Denmark

\section{Key Points for Decision Makers}

Using a VivaSight double-lumen tube (VivaSight-DL) is cost effective compared with using a conventional double-lumen tube (cDLT) and reusable bronchoscopes.

The use of a bronchoscope to verify correct tube placement can be significantly reduced with the use of VivaSight-DL.

VivaSight-DL is easy to place and is associated with significantly less repositioning both during intubation and during the procedure. 
resections. In Denmark, approximately 2100 OLV procedures are conducted annually [6]. OLV procedures are common in clinical settings and are generally considered safe, with only minor complications such as sore throat, fever, and hoarseness $[3,7,8]$. However, the reusable bronchoscopes used in various thoracic surgeries to check for and ensure correct placement of the DLT carry a risk of cross-contamination between patients and subsequent infection [8-11].

DLTs can be difficult to insert and are likely to move during changes in patient position and surgery, which may compromise patient safety and prolong surgery time $[5,12$, 13]. Furthermore, the gold standard practice is to check for correct tube placement using a fiberoptic or video-enabled bronchoscope both after tube insertion and after changing the patient's position to the final lateral surgical position, which further increases the risk of tube displacement $[7,14]$. Therefore, continuous visualization of the tube's position in the main bronchus is thought to ensure more accurate and safer tube placement, significantly reducing the number of failed intubations, and the time spent verifying placement $[5,12,13]$. The VivaSight-DL (ETView Medical Ltd./Ambu A/S, Ballerup, Denmark) is the only fully single-use DLT with an integrated camera, which allows for more accurate tube placement using continuous real-time visualization and airway control during the entire surgical procedure $[1,7,15]$.

Reusable bronchoscopes are thought to be associated with high repair costs, reprocessing costs, and possible transmission of infectious agents via cross-contamination, which further increases the economic burden $[3,7$, 8, 16-18]. Furthermore, using bronchoscopy to ensure correct tube placement may prolong the intubation procedure time compared with VivaSight-DL, which allows for immediate confirmation of tube placement with continuous visualization $[12,19]$. Incorrect placement of the DLT can lead to problems with deflating the lung or with ventilating the non-operative lung sufficiently. Therefore, visual confirmation of correct tube placement after intubation and after placing the patient in the lateral surgical position has become mandatory $[5,15]$. Since its introduction in 1982, fiberoptic bronchoscopy has been used to confirm and maintain proper placement of the tube during OLV. However, studies have shown that fiberoptic bronchoscopy is associated with a high incidence of malposition (35-48\%), leading to additional time spent on subsequent repositioning $[15,20,21]$.

In addition, reusable bronchoscopes incur costs related to purchasing, reprocessing (involving high-level disinfection), and general maintenance and repair, which are all expected to increase in the future given the expected larger disease burden and more hospitals conducting more procedures annually $[15,22,23]$. The objective of this study was to investigate the cost effectiveness of using VivaSight-DL instead of cDLTs.

\section{Methods}

\subsection{Study Design}

A decision analytic model was constructed to assess the potential costs and effects associated with VivaSight-DL compared with a cDLT in a cost-effectiveness analysis (Fig. 1). Costs of reusable bronchoscopes, including capital costs and costs associated with reprocessing, personnel, maintenance, and repair, were obtained using a 10 -year time horizon. Costs related to VivaSight-DL were obtained using a 24-h time horizon. All costs are presented in \$US, and adjusted to year 2018 values, with a discount rate of 3.5\% regarding capital expenditures. The effectiveness measure for the cost-effectiveness analysis (CEA) was the number of times that fiberoptic confirmation of the tube placement during intubation or surgery was unnecessary and thus avoided. Effect data were obtained from a randomized controlled trial (RCT) and used to inform the decision model. The analysis was conducted from a healthcare sector perspective in Denmark, and the decision analytic model was constructed using the software TeeAgePro 2018 (TreeAge Software, Inc, Massachusetts, USA) (Fig. 1).

\subsection{Trial Design}

In the RCT, 50 patients were randomly assigned to two groups using a computer-generated random number list (http://www.randomizer.org). The intervention group was assigned to undergo intubation using VivaSight-DL, and the control group was assigned to undergo intubation using a cDLT (Shiley ${ }^{\mathrm{TM}}$ Medtronic, Minnesota, USA). Dropouts in both groups meant it was necessary to randomly assign

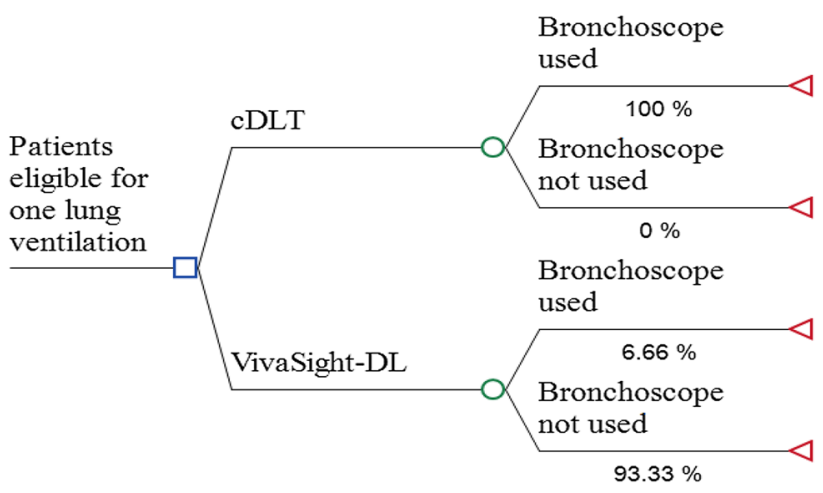

Fig. 1 Decision analytic model for cost effectiveness of VivaSightdouble-lumen (DL) tube vs. conventional double-lumen tube (cDLT) 
20 additional subjects to reach a total minimum number of 50 fully evaluable patients.

\subsubsection{Study Population}

Patients were eligible for inclusion if they were admitted to Unit BTY, Department V, Odense University Hospital (OUH), Denmark, and if they were evaluated as being eligible for an OLV with the use of a left-sided DLT. Patients were excluded if they had known tracheobronchial anatomic anomalies or tracheal pathology, had anticipated difficult airways, were aged $<18$ years, were undergoing an emergency procedure, required rapid sequence induction or right-sided DLT, had a prior systematic infection or suspected tuberculosis, or were unsuited for intubation with a DLT (VivaSight-DL or cDLT). Lastly, patients who needed surgeries in which the use of other lung isolation devices or techniques was likely to be warranted (tracheostomy, nasal intubation, etc.) were excluded. Physicians were eligible for participation if they had experience with DLT-associated intubations involving fewer than 50 patients, had completed the simulation training course, and had experience with at least ten cDLT placements and three VivaSight-DL placements involving a training manikin. Novice physicians were included to reflect real-world clinical settings, as the RCT was conducted at a university hospital.

\subsection{Resource Use and Costs}

Data on the utilization of resources and unit costs related to the cDLT and reusable bronchoscopes were obtained from OUH. All costs occurring before 2018 were adjusted using the average consumer price index for the year the cost occurred [24]. Finally, all costs were converted to \$US (exchange rate $\$$ US $1=$ DKK6.55; 7 February 2019).

\subsubsection{Micro-Costing Analysis}

A micro-costing analysis was carried out to obtain cost inputs for the CEA. The micro-costing approach was chosen because it allows for precise assessment of economic costs [25]. The purpose of the analysis was to determine the cost per use of a cDLT with a reusable bronchoscope compared with the cost per use of VivaSight-DL. Regarding the VivaSight-DL group, in cases in which bronchoscopy was required, both a single-use bronchoscope (aScope ${ }^{\mathrm{TM}}$ 4 Broncho, Ambu A/S) and reusable bronchoscopes were considered in the analysis.

Therefore, several procedures involving bronchoscopy and the reprocessing procedure were observed in detail. All capital costs related to the cleaning equipment, including the automated endoscope reprocessor (AER) and the drying cabinets, were amortized over an 8 -year period. The 8-year amortization period was based on the average age of the drying cabinets and AER. A discount rate of 3.5\% was used to calculate the present value of capital expenditures. Reusable bronchoscopes were amortized over a 6-year period, which was selected based on the average age of the six bronchoscopes currently available at OUH [26, 27]. The micro-costing analysis was carried out in regards to capital costs, reprocessing costs, and repair and maintenance costs.

Additionally, the total intubation time, number of intubation attempts, number of times the tube needed to be repositioned during surgery, and time spent by the backup anesthesiologist assisting the novice physician were accurately assessed during the RCT. The intubation time was defined as the time from introduction of the laryngoscope blade into the patient's mouth until correct tracheal cuff placement confirmed by capnography. All clinical data were measured and obtained by the physicians and other personnel themselves. Lastly, a total of ten bronchoscopy procedures were monitored by the investigator to estimate the average time spent on bronchoscopy involving a fiberoptic or video-enabled bronchoscope.

\subsubsection{Reprocessing and Repair Costs}

Cost estimates related to reprocessing and repair of the reusable bronchoscopes were based on the six bronchoscopes available at Unit BTY, Department V, OUH. This analysis involved the mean annual number of bronchoscopy procedures $(n=600)$, mean reprocessing time, and mean annual cost of repairs. Maintenance of the reprocessing equipment was managed by medical engineers at $\mathrm{OUH}$, and no records were kept of previous repairs or services, so these costs were based on the literature adjusted by $-20 \%$ to avoid overestimation [28]. Materials related to reprocessing such as consumables were accounted for. Reprocessing costs were divided into costs for reprocessing equipment, manual precleaning, drying, and AER running costs. A detailed description of the reprocessing materials and costs is provided in Table 1. The hourly wage of cleaning personnel was calculated based on 2018 wages and an estimate of 1500 productive working hours annually. Costs related to the training and education of cleaning personnel were not included, as these data were not available at OUH. Purification of the water used by the AER was centralized in the basement of the hospital and thus a water disinfector was not required. Therefore, it was not possible to calculate the costs of purifying the water.

\subsection{Effectiveness Measure}

The number of times that fiberoptic confirmation of the tube placement during intubation or surgery was unnecessary and thus avoided was chosen as the effectiveness measure. The effectiveness measure was chosen due to the assumption that fiberoptic confirmation using a bronchoscope is both time 
Table 1 Reprocessing equipment. All unit costs are estimated based on data from Odense University Hospital. Estimated costs of maintenance are based on the literature [28]

\begin{tabular}{|c|c|}
\hline Item & $\begin{array}{l}\text { Cost per item/ } \\
\text { procedure }(\$ U S)\end{array}$ \\
\hline \multicolumn{2}{|l|}{ Reprocessing equipment } \\
\hline AER & 21.10 \\
\hline Drying cabinet 1 & 9.25 \\
\hline Drying cabinet 2 & 9.25 \\
\hline Drying cabinet 3 & 9.25 \\
\hline Maintenance-drying cabinets & 35.44 \\
\hline Maintenance-AER & 50.53 \\
\hline \multicolumn{2}{|l|}{ Manual precleaning } \\
\hline Brushes & 4.93 \\
\hline Sterile water & 0.12 \\
\hline Ethanol & 0.06 \\
\hline ATP water effluent test & 0.27 \\
\hline Plastic packaging & 0.69 \\
\hline Non-sterile gloves & 0.07 \\
\hline Sterile wash gown & 0.11 \\
\hline Cover (for transport) & 1.02 \\
\hline Plastic cover (for transport) & 0.97 \\
\hline Bodedex $^{\circledR}$ forte $^{\mathrm{a}}$ & 4.16 \\
\hline High-clean non-woven swabs & 0.09 \\
\hline Water & 0.15 \\
\hline Cleaning personnel & 4.41 \\
\hline \multicolumn{2}{|l|}{ Drying } \\
\hline Cleaning personnel & 0.88 \\
\hline Power & 1.8 \\
\hline \multicolumn{2}{|l|}{ AER running costs } \\
\hline DLC endoscope detergent ${ }^{\mathrm{b}}$ & 1.22 \\
\hline Aperlan $\mathrm{A}^{\mathrm{b}}$ & 3.00 \\
\hline Aperlan $\mathrm{B}^{\mathrm{b}}$ & 3.04 \\
\hline Power & 1.8 \\
\hline Water & 0.41 \\
\hline Cleaning personnel (daily cleaning) & 3.53 \\
\hline Total & 167.55 \\
\hline
\end{tabular}

AER automated endoscope reprocessor

${ }^{a}$ BODE Chemie GmbH, Hamburg, Germany

${ }^{\mathrm{b}}$ Getinge Sterilization AB, Getinge, Sweden

consuming and costly. Although intubation time is an indicator of the relative ease of correct tube placement, it is not a sufficient effectiveness measure, as it reflects physician competences and varies greatly between patients because of differences in airway anatomy and health status.

\subsection{Sensitivity Analyses}

A number of one-way analyses were conducted to assess the impact on the incremental cost-effectiveness ratio (ICER) of varying the percentage of VivaSight-DL cases in which fiberoptic confirmation with a single-use bronchoscope (aScope ${ }^{\mathrm{TM}} 4$ Broncho) was needed $(5 \%, 10 \%$, and $15 \%)$ and by increasing the annual number of bronchoscopy procedures $(800,1000$, and 1200). When increasing the annual number of bronchoscopy procedures, the annual repair and maintenance costs were proportionally increased, and the amount of detergent used for the AER was increased. Furthermore, the maintenance cost was decreased by an additional $10 \%, 20 \%$, and $30 \%$, respectively, as the maintenance cost was based on the literature [28] and may be slightly overestimated compared with current clinical settings at OUH (i.e., the baseline cost was based on the literature and adjusted by $-20 \%$ ). Lastly, the capital cost of the VivaSightDL device was decreased by $10 \%, 20 \%$, and $30 \%$ to account for differences between countries.

A two-way sensitivity analysis was conducted to assess the impact of cost levels regarding VivaSight-DL and cDLTs with reusable bronchoscopes. The analysis included all costs directly related to the use of cDLTs with reusable bronchoscopes. Moreover, a probabilistic sensitivity analysis (PSA) was conducted to simultaneously test the impact of the different variables and to assess the robustness of the result (Table 2). A second-order Monte Carlo simulation with 10,000 simulations was used for the PSA. Gamma distributions were applied to all cost variables, as this distribution allows for right skewness and because the cost variables can only take a positive value. Beta distributions were applied to the probability variables, as the probabilities can only lie between zero and one.

\subsection{Statistics}

All non-cost data obtained from the RCT were stored and managed using Smart-Trial (http://www.smart-trial.com) and exported to and analyzed using Microsoft Excel 2016. All cost data were stored and analyzed in Excel. For both the intervention and control groups, means and standard deviations (SDs) were determined for the baseline patient characteristics, comprising age, weight, height, and body mass index. Two-sided Fisher's exact tests were used to test for statistically significant differences between sex and number of patients who had a tube repositioning in the intervention and control groups. Furthermore, a two-sided Wilcoxon rank sum test was used to determine whether there was a statistically significant difference in age, height, weight, intubation attempts, intubation time, Cormack-L classification (classification used to describe laryngeal view during direct laryngoscopy [29]), use of fiberoptic bronchoscopy, prevention of repositioning, repositioning time, and time spent by responsible anesthesiologists to assist repositioning between the two groups. A statistical significance level of 0.05 was applied. 
Table 2 Model inputs: parameter values and their respective standard errors, distributions and source

\begin{tabular}{|c|c|c|c|}
\hline Parameter & Base-case value (SE) & Distribution & Source \\
\hline \multicolumn{4}{|l|}{ Effects } \\
\hline cDLT and reusable colonoscope: avoided bronchoscopy & $0 \%$ & Beta & $\begin{array}{l}\text { RCT per- } \\
\text { formed at } \\
\text { OUH (see } \\
\text { Sect. 2.2) }\end{array}$ \\
\hline VivaSight-DL: avoided bronchoscopy & $93.33 \%$ & Beta & $\begin{array}{l}\text { RCT per- } \\
\text { formed at } \\
\text { OUH (see } \\
\text { Sect. 2.2) }\end{array}$ \\
\hline \multicolumn{4}{|l|}{ Cost } \\
\hline Cost per use of cDLT and reusable colonoscope & $347.61(16.8)$ & Gamma & OUH \\
\hline Cost per use of VivaSight-DL (incl. Ambu ${ }^{\circledR} \mathrm{aView}^{\mathrm{TM}}$ ) & $299.96(12)$ & Gamma & Ambu A/S \\
\hline
\end{tabular}

$c D L T$ conventional double-lumen tube, $D L$ double-lumen tube, $O U H$ Odense University Hospital, $R C T$ randomized controlled trial, $S E$ standard error

\section{Results}

\subsection{Patient Characteristics}

Of the 70 patients assessed, 18 were excluded from the study. All patients were admitted to Unit BTY, Department $\mathrm{V}$, OUH for thoracic surgery from 5 November 2018 to 23 January 2019. Of the remaining 52 eligible patients, 30 were allocated to the intervention group (VivaSight-DL) and 22 to the control group (cDLT). In the intervention group, the mean age was 65.8 years and 13 patients (43.3\%) were female. In the control group, the mean age was 68.5 years and 12 patients $(54.5 \%)$ were female. While having limited statistical power, there were no significant differences in sex $(p=0.58)$, age $(p=0.44)$, height $(p=0.76)$, weight $(p=0.69)$, or Cormack-L classification $(p=0.98)$ between the intervention and control groups $(p=0.71)$. All baseline patient characteristics are shown in Table 3.

\subsection{Micro-Costing Analysis}

All costs related to cDLT use, including reprocessing, maintenance, repair, and personnel, were calculated as the cost per procedure. The total cost of performing an intubation using a cDLT with bronchoscopy to verify the tube placement is \$US347.61. The cost includes an additional cost of $67.88 \mathrm{~s}$ extra time spent on bronchoscopy, which amounts to an additional cost of \$US39.60 using an estimated operating room running cost of \$US35.00 per minute [30-32]. The total cost of performing an intubation using VivaSight-DL is \$US299.96, including the cost of an $\mathrm{Ambu}^{\circledR}{ }^{\mathrm{aView}}{ }^{\mathrm{TM}}$ monitor (Ambu A/S, Ballerup, Denmark). The costs related to each intervention are specified in Table 4. Regarding the cost of each major activity involved in using a cDLT with bronchoscopy, the
Table 3 Baseline patient characteristics of the randomized controlled trial

\begin{tabular}{lll}
\hline & VivaSight-DL $(n=30)$ & cDLT $(n=22)$ \\
\hline Age, years & $65.8 \pm 10.0$ & $68.5 \pm 7.2$ \\
Female & $13(43.3)$ & $12(54.5)$ \\
Male & $17(56.7)$ & $10(45.5)$ \\
Weight, kg & $74.7 \pm 19.1$ & $76.2 \pm 17.1$ \\
Height, cm & $172.5 \pm 9.3$ & $172.8 \pm 9.6$ \\
Body mass index, $\mathrm{kg} \cdot \mathrm{cm}^{2}$ & $24.9 \pm 5.2$ & $25.6 \pm 4.4$ \\
Cormack-L classification & & \\
I & $18(60.0)$ & $14(63.6)$ \\
II & $10(33.3)$ & $5(22.7)$ \\
III & $1(3.3)$ & $1(4.5)$ \\
IV & $1(3.3)$ & $2(9.1)$ \\
\hline
\end{tabular}

Data are presented as mean \pm standard deviation or $n(\%)$

Cormack-L-classifications: (1) full view of glottis; (2) partial view of glottis; (3) only view of epiglottis; (4) no view of either glottis or epiglottis

$c D L T$ conventional double-lumen tube, $D L$ double-lumen tube

reprocessing cost (including the reprocessing equipment and personnel) was \$US81.61 per procedure, the cost of reprocessing equipment maintenance was \$US86.04, and the bronchoscope repair cost was \$US77.13. In 2018, the six bronchoscopes were repaired for a total of \$US46,293.32. Capital costs, year of purchase, and repair cost of the bronchoscopes are provided in Table 5 .

The time spent by cleaning personnel on manually handling the bronchoscopes after each procedure amounted to a total of $15 \pm 2.76 \mathrm{~min}$. A detailed description of the time allocation is listed in Table 6. Intubation time was measured for each procedure, and the average intubation time was $1.66 \pm 0.89 \mathrm{~min}$ in the intervention group and $1.43 \pm 0.80 \mathrm{~min}$ 
Table 4 Overall cost categories (\$US per procedure) for both interventions (VivaSight-DL vs. cDLT)

\begin{tabular}{llc}
\hline Cost category & VivaSight-DL & cDLT \\
\hline Capital costs & $\begin{array}{l}\text { VivaSight-DL: 299.00 } \\
\text { Ambu }{ }^{\circledR} \text { aView }{ }^{\text {TM: }} \text { 0.94 }\end{array}$ & $\begin{array}{c}\text { Reusable } \\
\text { bron- } \\
\text { cho- }\end{array}$ \\
& & scope: \\
& & 27.01 \\
& & $\begin{array}{c}\text { Dispos- } \\
\text { able }\end{array}$ \\
& & tube: \\
& & 35.41 \\
Repair cost & None & 77.13 \\
Maintenance & None & 86.04 \\
Backup anesthesiologist & $0.02^{\mathrm{a}}$ & $0.80^{\mathrm{b}}$ \\
Cleaning supplies and equip- & None & 72.79 \\
ment & & 8.82 \\
Cleaning personnel & None & 39.60 \\
Operating room running cost & None & 347.61 \\
Total cost & 299.96 &
\end{tabular}

$c D L T$ conventional double-lumen tube, $D L$ double-lumen tube

${ }^{a}$ The backup anesthesiologist spent $18 \mathrm{~s}$ on repositioning in the intervention group

${ }^{\mathrm{b}}$ The backup anesthesiologist spent $520 \mathrm{~s}$ on repositioning in the control group

in the control group $(p=0.20)$. The average number of intubation attempts was $1.23 \pm 0.50$ in the intervention group and $1.14 \pm 0.47$ in the control group ( $p=0.44)$. However, in the intervention group, the tube was only repositioned in three patients (total of four repositions, maximum two repositions per patient) before correct tracheal cuff placement was confirmed by capnography, which is significantly less than in the control group, in which the tube was repositioned in 11 patients (total of 20 repositions, maximum seven repositions per patient) before capnography $(p=0.0034)$. After capnography, the tube was repositioned in seven patients (total of ten repositions, maximum three repositions per patient) from the intervention group and in 12 patients (total of 17 repositions, maximum three repositions per patient) from the control group $(p=0.04)$. The average time spent on the repositioning during surgery was $60.86 \pm 73.09 \mathrm{~s}$ in the intervention group and $144.42 \pm 152.86 \mathrm{~s}$ in the control group $(p=0.06)$. In total, the backup anesthesiologist assisted with repositioning the tube once in the intervention group and three times in the control group. The backup anesthesiologist spent $18 \mathrm{~s}$ on repositioning in the intervention group and $520 \mathrm{~s}$ (mean $173.33 \pm 115.47)$ in the control group $(p=1.00)$. The additional cost of having the backup anesthesiologist assisting with repositioning was \$US0.61 in the intervention group and \$US17.64 in the control group.

\subsection{Base-Case and Sensitivity Analyses}

The base-case analysis showed an average cost of a cDLT with a reusable bronchoscope of \$US347.61, and a bronchoscope was used to verify correct placement in all cases involving a cDLT. The ICER was - \$US51.06 per bronchoscopy avoided. Generally, fiberoptic confirmation is needed
Table 5 Capital and repair costs (\$US) of reusable bronchoscopes in 2018
Table 6 Average personnelrelated reprocessing costs (\$US). All manual reprocessing is carried out by trained cleaning personnel at Odense University Hospital. Times spent on reprocessing were obtained by observing several reprocessing procedures

\begin{tabular}{lcll}
\hline Item & Capital costs & Year of purchase & Repair costs \\
\hline Fiberoptic bronchoscope & 6390.15 & 2016 & 0 \\
Fiberoptic bronchoscope & 6099.71 & 2016 & 0 \\
Fiberoptic bronchoscope & 7355.03 & 2009 & 1633.59 \\
Video-enabled bronchoscope & $24,200.26$ & 2008 & $25,900.70$ \\
Video-enabled bronchoscope & $23,889.46$ & 2009 & $10,373.47$ \\
Video-enabled bronchoscope $^{\text {Cost per procedure }}$ & $18,460.41$ & 2014 & 8385.58 \\
\hline
\end{tabular}

OUH Odense university hospital

${ }^{a}$ Cost per procedure was identified using the annual number of procedures performed at OUH $(n=600)$

\begin{tabular}{lll}
\hline Job description related to reprocessing & $\begin{array}{l}\text { Average minutes spent on reprocessing } \\
\text { after each procedure }\end{array}$ & $\begin{array}{l}\text { Average cost of } \\
\text { reprocessing }\end{array}$ \\
\hline Transportation of bronchoscopes & 0.5 & 0.29 \\
Manual precleaning & 6 & 3.53 \\
Cleaning of worktable and table cart & 1 & 0.59 \\
Placement in drying cabinets & 1.5 & 0.88 \\
$\begin{array}{l}\text { Daily cleaning of automated endoscope repro- } \\
\text { cessor }\end{array}$ & 6 & 3.53 \\
\hline
\end{tabular}


twice when using a cDLT; however, in this study, fiberoptic confirmation was needed an average of $3.14 \pm 1.58$ times per procedure. In comparison, fiberoptic confirmation was only used two times for all the VivaSight-DL procedures (6.66\% of the procedures), resulting in a significantly lower average bronchoscope use of $0.07 \pm 0.25$ times per procedure $(p<0.001)$. Moreover, only one of the fiberoptic confirmations was related to the use of VivaSight-DL, whereas the other was used to check for bleeding and tumor mass in the lower respiratory tract. The average cost of VivaSight-DL including the need for a bronchoscope in $6.66 \%$ of the procedures was \$US299.96. Thus, the base-case results indicated that VivaSight-DL was less costly and more effective than cDLT in regard to fiberoptic confirmation. Table 7 presents the base-case results along with an overview of the oneway sensitivity analyses. Figure 2 shows that the equivalence point is $15.8 \%$, which is the percentage of VivaSight-DL cases involving verifying correct tube placement using a single-use bronchoscope (aScope ${ }^{\mathrm{TM}} 4$ Broncho) at which point VivaSight-DL is no longer associated with cost savings.

Figure 3 shows the results of the two-way analyses, illustrating which of the two interventions is more advantageous when adjusting for the cost of VivaSight-DL and the cost of cDLTs with reusable bronchoscopes. Additionally, the PSA indicates that VivaSight-DL is more effective for avoiding fiberoptic confirmation with a bronchoscope and less costly than cDLTs, as $100 \%$ of all the calculated ICERs are located in the south-eastern quadrant. A scatterplot of the PSA results is shown in Fig. 4, with an ellipse indicating the $95 \%$ confidence interval.

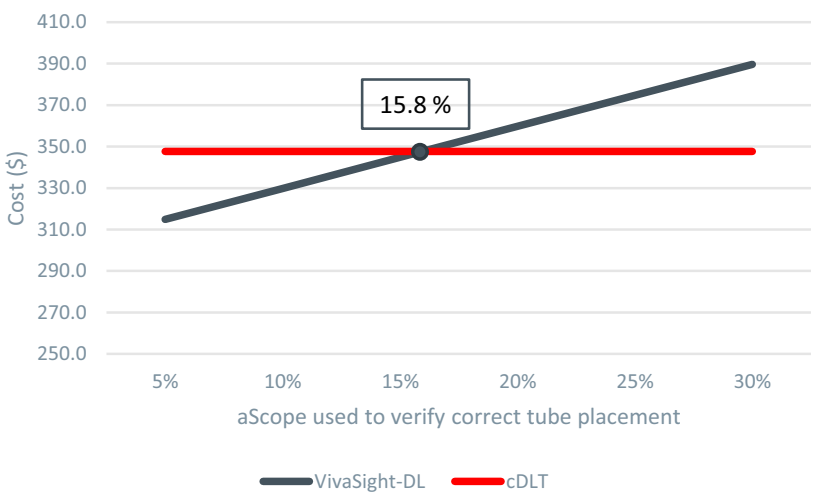

Fig. 2 Equivalence point for when VivaSight-DL used with a singleuse bronchoscope (aScope ${ }^{\mathrm{TM}} 4$ Broncho) no longer is associated with cost savings. Annual number of procedures: 600. $c D L T$ conventional double-lumen tube, $D L$ double-lumen tube

\section{Discussion}

This study is the first to report the results of an economic evaluation comparing the use of VivaSight-DL and a cDLT in OLV procedures. The cost of using VivaSight-DL was \$US299.96 per procedure, and the cost of using a cDLT with bronchoscopy was \$US347.61, leading to an annual saving of approximately \$US28,600 (13.7\%) if all cDLTs were substituted with VivaSight-DL at OUH. Reprocessing, maintenance, and repairs of reusable bronchoscopes contributed to approximately $80 \%$ of the total cost in the control

Table 7 Base-case result and one-way sensitivity analyses

\begin{tabular}{|c|c|c|c|}
\hline Scenario & $\Delta$ cost & $\begin{array}{l}\Delta \text { effect (avoided } \\
\text { bronchoscopy) }\end{array}$ & $\begin{array}{l}\text { ICER (cost per } \\
\text { avoided bronchos- } \\
\text { copy) }\end{array}$ \\
\hline Base case & -47.66 & 0.9333 & -51.06 \\
\hline \multicolumn{4}{|l|}{ One-way sensitivity analyses } \\
\hline Using single-use bronchoscope (aScope $\left.{ }^{\mathrm{TM}}\right)$ in $5 \%$ of all VivaSight-DL cases $(n=30)$ & -32.71 & 0.9500 & -34.43 \\
\hline Using single-use bronchoscope (aScope $\left.{ }^{\mathrm{TM}}\right)$ in $10 \%$ of all VivaSight-DL cases $(n=60)$ & -17.76 & 0.9000 & -19.73 \\
\hline Using single-use bronchoscope (aScope $\left.{ }^{\mathrm{TM}}\right)$ in $15 \%$ of all VivaSight-DL cases $(n=90)$ & -2.81 & 0.8500 & -3.30 \\
\hline Increasing annual number of procedures, $n=800$ & -41.22 & 0.9333 & -44.17 \\
\hline Increasing annual number of procedures, $n=1000$ & -103.30 & 0.9333 & -110.68 \\
\hline Increasing annual number of procedures, $n=1200$ & -168.02 & 0.9333 & -180.03 \\
\hline Decreasing maintenance costs by additional $10 \%(n=600)$ & -39.05 & 0.9333 & -41.84 \\
\hline Decreasing maintenance costs by additional $15 \%(n=600)$ & -34.75 & 0.9333 & -37.23 \\
\hline Decreasing maintenance costs by additional $20 \%(n=600)$ & -30.45 & 0.9333 & -32.62 \\
\hline Decreasing cost of VivaSight-DL by $10 \%(n=600)$ & -77.65 & 0.9333 & -83.20 \\
\hline Decreasing cost of VivaSight-DL by $20 \%(n=600)$ & -107.65 & 0.9333 & -115.34 \\
\hline Decreasing cost of VivaSight-DL by $30 \%(n=600)$ & -137.64 & 0.9333 & -147.48 \\
\hline
\end{tabular}

Costs are presented in \$US

cDLT conventional double-lumen tube, $D L$ double-lumen tube 
Fig. 3 Two-way sensitivity analyses. The blue area indicates savings from using VivaSight-DL and the red area indicates savings from using reusable bronchoscopes. $D L$ double-lumen tube

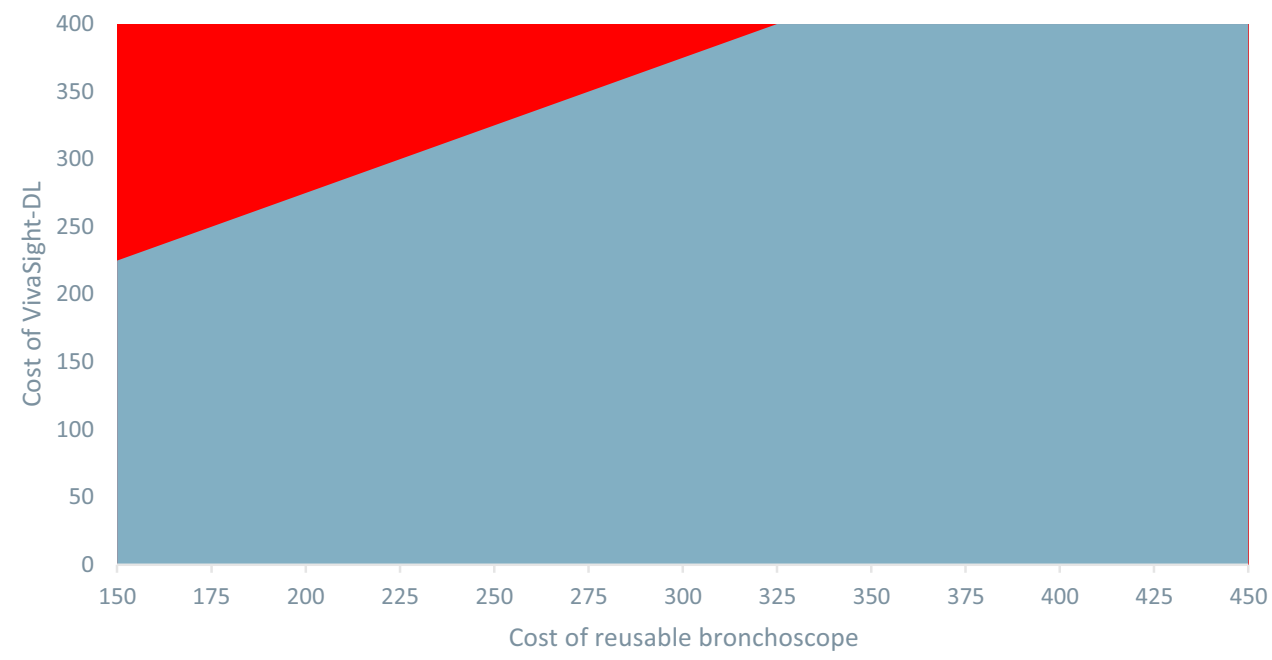

group. Furthermore, bronchoscopy was only necessary in two $(6.66 \%)$ cases involving VivaSight-DL, and only one of these cases was necessitated by issues with the device (i.e., the novice physician was unable to sufficiently clean the camera lens due to secretions and blood). The ICER in this study was - \$US51.06 per bronchoscopy avoided. As the ICER was negative, it can be difficult to interpret, as the intervention (VivaSight-DL) is already showing a greater effect and lower costs than using cDLT with bronchoscopy. Therefore, VivaSight-DL will always lead to a saving in regards to cost per avoided bronchoscopy, which raises questions over whether it makes sense to interpret a negative ICER in a case like this. Sensitivity analyses supported the findings of this study. However, the use of VivaSight-DL with a bronchoscope is only associated with cost savings when using a single-use bronchoscope (aScope ${ }^{\mathrm{TM}} 4$ Broncho). Figure 2 illustrates that an aScope ${ }^{\mathrm{TM}} 4$ Broncho can be used with VivaSight-DL in up to 95 VivaSight-DL procedures annually (15.8\%) and still be more cost saving than cDLTs with reusable bronchoscopes. VivaSight-DL is most likely not associated with cost savings if used with a reusable bronchoscope because of the high costs related to capital costs, reprocessing, maintenance, and repair of the reusable bronchoscopes. Thus, VivaSight-DL will only function as a more expensive tube and the advantages of the embedded camera will be inessential.

The main limitations of this study are the fact that the novice intubating physicians were not blinded to the device they were using, thus increasing the risk of potential biases. Another limitation is that all clinical data were measured and obtained by the novice physicians and other personnel themselves, which may increase the risk of biases compared with data collected by a study nurse or an unbiased investigator. However, the chosen effectiveness measure was not sensitive to measurements as it was simple to identify whether a bronchoscope was used or not during the procedure. Furthermore, the chosen effectiveness measure in this study is not a health-related measure, which constitutes another weakness, as health-related effectiveness measures are preferred in health economics [33]. However, health-related effects can be difficult to obtain when working with medical devices such as DLTs. The effect of the device cannot be measured directly on the patient, and the patients cannot assess the effect themselves as they are under full anesthesia. Costs related to training and education of cleaning personnel were not included as these data were not available, which constitutes another limitation. Lastly, dropouts meant it was necessary to enroll an additional 20 patients to reach a minimum
Fig. 4 Scatterplot from the probabilistic sensitivity analysis. $100 \%$ of the iterations are located in the south-eastern quadrant. The ellipse indicates the $95 \%$ confidence interval

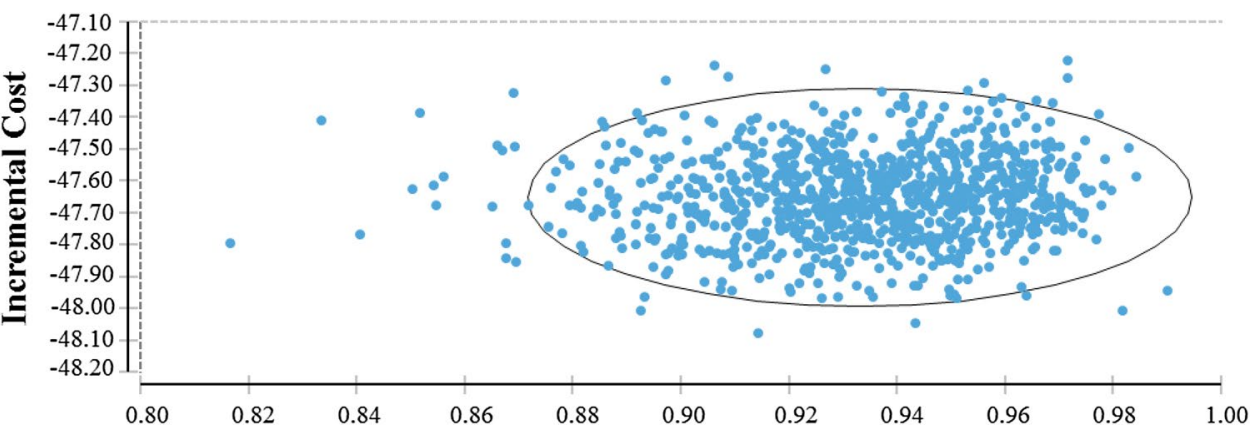


of 50 eligible patients in the RCT. As an unequal number of patients were excluded from each group, an imbalance was created (30 vs. 22 patients), which was another limitation.

Uncertainties regarding costs were accounted for in the different sensitivity analyses; VivaSight-DL was associated with cost savings in every scenario compared with a cDLT. Multiple studies have already documented the numerous superior effects of VivaSight-DL compared with cDLTs in clinical settings, which further underlines the advantage of using VivaSight-DL as a tool for intubation in OLV procedures [1, 4, 5, 12, 15]. Levy-Faber et al. [5] and Schuepbach et al. [12] found that bronchoscopy was unnecessary when intubating patients with VivaSight-DL, which supports the findings of this study indicating that bronchoscopy use can be minimized when using VivaSight-DL. When used by experienced physicians, VivaSight-DL may result in even fewer bronchoscopies, but this was not assessed in this study. Levy-Faber et al. [5] found that VivaSight-DL enables significantly quicker intubation compared with a cDLT, which is further supported by the findings of an RCT published by Heir et al. [15] in 2018. However, the current study showed that the intubation time was prolonged when using VivaSight-DL compared with a cDLT $(p=0.35)$. The prolonged intubation time was mainly because of one outlier and may be because the novice physicians had more experience with placing cDLTs than with VivaSight-DL. In addition, one physician mentioned that the continuous visualization meant the tube placement was more thorough in the VivaSight-DL group. Another study by Heir et al. [2] published in 2014 demonstrated that video-enabled DLT required fiberoptic confirmation of tube placement (for both initial placement and final verification after the patient was placed in the lateral surgical position) in significantly fewer cases (6.8\%). Heir et al. [2] emphasized that this is in contrast to current standard practice, which always requires bronchoscopy for confirmation of correct tube placement, and that the addition of an integrated camera may increase patient safety [34].

The clinical advantages of VivaSight-DL are welldocumented, and the complete elimination of any risk of device-related cross-contamination because of its singleuse modality is a major benefit $[2,5,35,36]$. However, if VivaSight-DL is used together with a reusable bronchoscope, the risk of cross-contamination will once again be present $[2,5]$. Currently, none of the clinical advantages have been assessed in terms of the cost effectiveness of VivaSight-DL compared with cDLTs. Contaminated bronchoscopes have been linked to many nosocomial infections, although the true incidence of these infections is unknown because of inadequate surveillance [35-37]. Reusable bronchoscopes can be reprocessed, but they cannot be sterilized, which increases the risk of colonization by biofilm-producing species $[35,38,39]$. Additionally, although maintenance costs were estimated from the literature and adjusted by $-20 \%$, the cost of purifying the water used by the AER was not included and neither were the other general overhead costs. Numerous minor costs contribute to the overall cost per procedure involving a cDLT, such as exact water consumption, electricity, and regular training and education of new cleaning personnel. Furthermore, time spent remaining up to date and compliant with guidelines regarding reprocessing and handling of flexible bronchoscopes along with reporting failures of reprocessing equipment all contribute to the overhead costs. These overhead costs are difficult to estimate and include in economic evaluations, and economic evaluations often lack precision in terms of including all overhead costs $[3,16,22,40]$. If all cost drivers were identified and included in the analysis, the cost per procedure involving a cDLT would inevitably increase and thereby make cDLTs with bronchoscopy an expensive choice [8, 22, 39]. Additionally, training costs associated with implementing a new intervention (i.e., VivaSight-DL) were not included, as the same method is used for intubation; the only difference is the embedded camera in the VivaSight-DL. Future studies should include aspects of both the clinical advantages of VivaSight-DL related to the use of bronchoscopy to verify correct tube placement, intubation time, and number of attempts, ease of insertion, and risk of cross-contamination and the economic aspects, to ensure a reasonable balance between both aspects.

\section{Conclusion}

The results of this study suggest that VivaSight-DL is associated with cost savings compared with a cDLT for OLV procedures. However, when used with a bronchoscope, VivaSight-DL is only associated with cost savings when used with a single-use bronchoscope. To clarify whether VivaSight-DL is cost saving in larger or global clinical settings, further economic evaluations should be performed.

Author Contributions Data collection, data analysis, and manuscript writing was performed by SL. All authors revised the manuscript for important intellectual content and approved the manuscript.

Data Availability All data input and details on modelling supporting this study are provided in the manuscript. Readers should be able to replicate the model in TreeAge, Microsoft ${ }^{\circledR}$ Excel, or other preferred software.

\section{Compliance with Ethical Standards}

Funding This study was non-financially supported by the Department of Anesthesiology and Intensive Care, Odense University Hospital, Denmark, and sponsored by the supplier of VivaSight-DL and aScope $^{\text {TM }} 4$ Broncho, Ambu A/S, Ballerup, Denmark. 
Conflict of interest Sara Larsen, Jimmy Højberg Holm, Tove Nørgaard Sauer, and Claus Andersen have no conflicts of interest that are directly relevant to the content of this article.

Open Access This article is distributed under the terms of the Creative Commons Attribution-NonCommercial 4.0 International License (http://creativecommons.org/licenses/by-nc/4.0/), which permits any noncommercial use, distribution, and reproduction in any medium, provided you give appropriate credit to the original author(s) and the source, provide a link to the Creative Commons license, and indicate if changes were made.

\section{References}

1. Rapchuk IL, Kunju SAM, Smith IJ, Faulke DJ. Original Papers A six-month evaluation of the VivaSight ${ }^{\mathrm{TM}}$ video doublelumen endotracheal tube after introduction into thoracic anaesthetic practice at a single institution. Anaesth Intensive Care. 2017;45(2):189-96.

2. Heir JS, Purugganan R, Jackson TA, Norman PH, Cata JP, Kosturakis A, et al. A retrospective evaluation of the use of videocapable double-lumen endotracheal tubes in thoracic surgery. J Cardiothorac Vasc Anesth [Internet]. 2014 [cited 2018 Jun 27];28(4):882-4. Available from: https://ac-els-cdn-com.zorac .aub.aau.dk/S105307701300623X/1-s2.0-S10530770130062 3X-main.pdf?_tid=d74125e9-b90c-4b79-a4ff-5636518026 bb\&acdnat=1530099876_09a306c7763801ab747abf1235215691.

3. Massot J, Dumand-Nizard V, Fischler M, Le Guen M. Evaluation of the double-lumen tube Vivasight-DL (DLT-ETView): a prospective single-center study. J Cardiothorac Vasc Anesth [Internet]. 2015 [cited 2018 Apr 8];29(6):1544-9. Available from: https ://ac-els-cdn-com.zorac.aub.aau.dk/S1053077015002839/1-s2.0S1053077015002839-main.pdf?_tid=aad86e66-c3f4-4468-923d8bffc939907d\&acdnat $=1523194781 \_3 f 285 d 13 a 535 f a b 7209 f$ bc415c29e73a.

4. Szarpak EMT-P L, Kurowski A, Zaśko P, Karczewska K, Czyzewski LR, Bogdanski L, et al. Double-lumen tube tracheal intubation in a manikin model using the VivaSight Double Lumen: a randomized controlled comparison with the Macintosh laryngoscope. Am J Emerg Med [Internet]. 2016 [cited 2018 Apr 8];13:100-12. Available from: https://ac-els-cdn-com.zorac.aub. aau.dk/S0735675715008591/1-s2.0-S0735675715008591-main. pdf? tid $=41141347-150 b-49 b f-85 d d-d a 40046$ eac $7 d \& a c d n a$ $\mathrm{t}=1523195060 \_246310595 \mathrm{e} 1 \mathrm{e} 6 \mathrm{f} 75 \mathrm{a} 0 \mathrm{dac} 462 \mathrm{cf} 625566$.

5. Levy-Faber D, Malyanker Y, Nir RR, Best LA, Barak M. Comparison of VivaSight double-lumen tube with a conventional double-lumen tube in adult patients undergoing video-assisted thoracoscopic surgery. Anaesthesia. 2015;70(11):1259-63.

6. Landspatientregisteret (LPR) Avanceret [Internet]. [cited 2019 May 16]. Available from: http://end2019.esundhed.dk/sundhedsre gistre/LPR/Sider/LPR06A.aspx.

7. Purohit A, Bhargava S, Mangal V, Parashar VK. Lung isolation, one-lung ventilation and hypoxaemia during lung isolation. Indian J Anaesth. 2015;59:606-17.

8. Terjesen CL, Kovaleva J, Ehlers L. Early assessment of the likely cost effectiveness of single-use flexible video bronchoscopes. PharmacoEconomics Open [Internet]. 2017;1(2):133-41. Available from: http://link.springer.com/10.1007/s41669-017-0012-9.

9. Kovaleva J, Peters FTM, Van Der Mei HC, Degener JE. Transmission of infection by flexible gastrointestinal endoscopy and bronchoscopy. 2013 [cited 2019 Jan 24]; Available from: https ://www.ncbi.nlm.nih.gov/pmc/articles/PMC3623380/pdf/zcm23 1.pdf.
10. Safety Communications \& Infections Associated with Reprocessed Flexible Bronchoscopes: FDA Safety Communication Infections Associated with Reprocessed Flexible Bronchoscopes: FDA Safety Communication [Internet]. 2015 [cited 2019 Feb 28]. Available from: http://www.fda.gov/MedicalDevices/Safety/Alert sandNotices/ucm462949.htm.

11. Ofstead CL, Quick MR, Eiland JE, Adams SJ. A glimpse at the true cost of reprocessing endoscopes: results of a pilot project [Internet]. [cited 2018 Dec 14]. Available from: http://www.iahcs mm.org.

12. Schuepbach R, Grande B, Camen G, Schmidt AR, Fischer H, Sessler DI, et al. Intubation with VivaSight or conventional leftsided double-lumen tubes: a randomized trial Intubation avec VivaSight ou tubes conventionnels à double lumière gauche: un essai randomisé. Can Anesthesiol Soc [Internet]. 2015 [cited 2018 Apr 8];62:762-9. Available from: https://link-springer-com.zorac .aub.aau.dk/content/pdf/10.1007\%2Fs12630-015-0329-8.pdf.

13. Koopman EM, Barak M, Weber E, Valk MJA, De Schepper RTI, Bouwman RA, et al. Evaluation of a new double-lumen endobronchial tube with an integrated camera (VivaSight-DL ${ }^{\mathrm{TM}}$ ): a prospective multicentre observational study. Anaesthesia. 2015;70(8):962-8.

14. Donn SM, Kuhns LR. Pediatric radiology mechanism of endotracheal tube movement with change of head position in the neonate [Internet]. Vol. 9, Pediatr Radiol. 1980 [cited 2019 Feb 19]. Available from: https://link-springer-com.zorac.aub.aau.dk/conte nt/pdf/10.1007\%2FBF00973968.pdf.

15. Heir J, Guo S-L, Purugganan R, Jackson TA, Sekhon AK, Mirza $\mathrm{K}$, et al. A randomized controlled study of the use of video doublelumen endobronchial tubes versus double-lumen endobronchial tubes in thoracic surgery. J Cardiothorac Vasc Anesth [Internet]. 2018 [cited 2018 Apr 8];32:267-74. Available from: https://acels-cdn-com.zorac.aub.aau.dk/S1053077017304949/1-s2.0-S1053 077017304949-main.pdf? tid=f8fb8256-4b10-439a-841b-6c5b5 7af80d1\&acdnat=1523194496_233b6c664f6a0a964d01f270f $4 \mathrm{~b} 349 \mathrm{c} 1$

16. Perbet $S$, Blanquet $M$, Mourgues $C$, Delmas J, Bertran $S$, Longère $\mathrm{B}$, et al. Cost analysis of single-use (Ambu ${ }^{\circledR}$ aScope $^{\mathrm{TM}}$ ) and reusable bronchoscopes in the ICU. 2017 [cited 2018 Sep 7];7:3. Available from: https://link.springer.com/content/pdf/10.1186\%2Fs13 613-016-0228-3.pdf.

17. Sato R, Gomez Rey G, Nelson S, Pinsky B. Community-acquired pneumonia episode costs by age and risk in commercially insured US adults aged $\geq 50$ years. Appl Health Econ Health Policy. 2013;11(3):251-8.

18. Kovaleva J. Infectious complications in gastrointestinal endoscopy and their prevention. Best Pract Res Clin Gastroenterol [Internet]. 2016 Oct;30(5):689-704. Available from: http://www. embase.com/search/results?subaction=viewrecord \&from $=$ expor t\&id=L613199150.

19. Saracoglu A, Saracoglu KT. VivaSight:a new era in the evolution of tracheal tubes. J Clin Anesth [Internet]. 2016;33:442-9. Available from: http://dx.doi.org/10.1016/j.jclinane.2016.04.034.

20. Natta;Kemp JCH Van. Devices for lung isolation used by anesthesiologists with limited thoracic experience: comparison of doublelumen endotracheal tube, Univent ${ }^{\mathbb{B}}$ Torque Control Blocker, and Arndt Wire-guided Endobronchial Blocker ${ }^{\circledR}$. Anesthesiology [Internet]. 2006 Feb 1 [cited 2019 Mar 3];104(2):261-6. Available from: https://insights.ovid.com/crossref?an=00000542-20060 2000-00010.

21. Klein U, Karzai W, Bloos F, Wohlfarth M, Gottschall R, Fritz $\mathrm{H}$, et al. Role of fiberoptic bronchoscopy in conjunction with the use of double-lumen tubes for thoracic anesthesia: a prospective study. Anesthesiology [Internet]. 1998 Feb 1 [cited 2019 Mar 3];88(2):346-50. Available from: http://www.ncbi.nlm.nih.gov/ pubmed/9477054. 
22. Tvede MF, Kristensen MS, Nyhus-Andreasen M. A cost analysis of reusable and disposable flexible optical scopes for intubation. Acta Anaesthesiol Scand. 2012;56(5):577-84.

23. Edenharter GM, Gartner D, Pförringer D. Decision support for the capacity management of bronchoscopy devices: optimizing the cost-efficient mix of reusable and single-use devices through mathematical modeling. Anesth Analg. 2017;124(6):1963-7.

24. Forbrugerprisindeks-Danmarks Statistik [Internet]. [cited 2019 Feb 28]. Available from: https://www.dst.dk/da/Statistik/emner/ priser-og-forbrug/forbrugerpriser/forbrugerprisindeks.

25. Xu X, Grossetta Nardini HK, Ruger JP. Micro-costing studies in the health and medical literature: protocol for a systematic review. Syst Rev [Internet]. 2014 Dec 21 [cited 2019 May 15];3(1):47. Available from: http://www.ncbi.nlm.nih.gov/pubmed/24887208.

26. Drummond MF, Sculpher MJ, Claxton K, Stoddart GL, Torrance GW. Methods for the economic evaluation of health care programmes. 2015. p. 242-244.

27. Weinstein MC, O'Brien B, Hornberger J, Jackson J, Johannesson M, McCabe C, et al. Principles of good practice for decision analytic modeling in health-care evaluation: report of the ISPOR task force on good research practices-modeling studies. Value Health. 2003;6(1):9-17.

28. Phan YC, Cobley J, Mahmalji W. Cost analysis and service delivery on using Isiris $\alpha^{\mathrm{TM}}$ to remove ureteric stents. J Endoluminal Endourol [Internet]. 2018;1(1):e3-e16. Available from: http:// jeleu.com/index.php/JELEU/article/view/5.

29. Krage R, Van Rijn C, Van Groeningen D, Loer SA, Schwarte LA, Schober P. Cormack-Lehane classification revisited. Br J Anaesth [Internet]. 2010 [cited 2019 May 16];105(2):220-7. Available from: https://academic.oup.com/bja/article-abstr act/105/2/220/247638.

30. Warner DO, Chung P, Lubarsky DA. Use of linear programming to estimate impact of changes perioperative variable costs. J Am Soc Anesthesiol. 2015;96(3):718-24.

31. Shippert RD. A study of time-dependent operating room fees and how to save $\$ 100000$ by using time-saving products. Am J Cosmet Surg [Internet]. 2005;22(1):25-34. Available from: http:// journals.sagepub.com/doi/10.1177/074880680502200104.

32. Macario A. What does one minute of operating room time cost? $\mathrm{J}$ Clin Anesth [Internet]. 2010 Jun 1 [cited 2018 Oct 4];22(4):2336. Available from: http://www.ncbi.nlm.nih.gov/pubmed/20522 350 .
33. Weinstein MC, Siegel JE, Gold MR, Kamlet MS, Russell LB. Recommendations of the panel on cost-effectiveness in health and medicine. JAMA J Am Med Assoc [Internet]. 1996 Oct 16 [cited 2019 Feb 25];276(15):1253. Available from: http://jama.jaman etwork.com/article.aspx?doi=10.1001/jama.1996.0354015005 5031.

34. Giglio M, Oreste D, Oreste N. Usefulness of ETView TVT endotracheal tube ${ }^{\circledR}$ for correct positioning of bronchial blockers in left lobectomy: an easy and safe combination. Minerva Anestesiol [Internet]. 2009 [cited 2019 Feb 27];75:1-4. Available from: http://www.siaarti.it.

35. Kovaleva J, Peters FTM, Van Der Mei HC, Degener JE. Transmission of infection by flexible gastrointestinal endoscopy and bronchoscopy. Am Soc Microbiol [Internet]. 2013 [cited 2018 Oct 4];26(2):231-54. Available from: http://cmr.asm.org/.

36. Srinivasan A, Wolfenden LL, Song X, Mackie K, Hartsell TL, Jones HD, et al. An outbreak of Pseudomonas aeruginosa infections associated with flexible bronchoscopes [Internet]. Vol. 348, n engl j med. 2003 [cited 2019 Feb 27]. Available from: http:// www.nejm.org.

37. Wang P, Xu T, Ngamruengphong S, Makary MA, Kalloo A, Hutfless $\mathrm{S}$. Rates of infection after colonoscopy and osophagogastroduodenoscopy in ambulatory surgery centres in the USA. Gut. 2018;67(9):1626-36.

38. Statens Serum institut. Nationale kliniske retningslinjer for genbehandling af fleksible endoskoper [Internet]. [cited 2018 Sep 12]. Available from: https://edit.ssi.dk/sitecore/shell/Controls/ Rich Text Editor// /media/Indhold/DK-dansk/Smitteberedskab/ Infektionshygiejne/NIR/NIR Endoskoper.ashx.

39. Al OC et al. The effectiveness of sterilization for flexible ureteroscopes: A real-world study. Am J Infect Control [Internet]. 2017;45(8):888-95. Available from: http://www.embase.com/ search/results?subaction $=$ viewrecord $\&$ from $=$ export $\&$ id $=$ L6168 25700 .

40. Gupta D, Wang H. Cost-effectiveness analysis of flexible optical scopes for tracheal intubation: a descriptive comparative study of reusable and single-use scopes. J Clin Anesth [Internet]. 2011 [cited 2018 Dec 14];23:632-5. Available from: https://ac-els-cdncom.zorac.aub.aau.dk/S0952818011003229/1-s2.0-S095281801 1003229-main.pdf?_tid=d479f491-6e44-47f9-93b3-3bbe58fee0 1b\&acdnat=1544789431_cbd6cf67b124f5004bce6c2ffc7aa6a0. 